\title{
LA DIDASCALIA, OLVIDADA FUNCIÓN ESENCIAL DE LA IGLESIA
}

\section{DIDASCALIA, A FORGOTTEN ESSENTIAL FUNCTION OF THE CHURCH}

\author{
Enrique García Ahumada, F.S.C. ${ }^{8}$ \\ Seminario Pontificio Mayor del Arzobispado de Santiago \\ Chile
}

\begin{abstract}
RESUMEN
Para demostrar que la didascalia o educación de cristianos es olvidada función esencial de la Iglesia en la normativa pastoral actual, se tratan los temas siguientes: 1) Minusvaloración de la función educativa de la Iglesia en la normativa pastoral actual. 2) La didascalia es función esencial de la Iglesia en los textos bíblicos sobre su fundación. 3) Jesús Maestro fundó la Iglesia esencialmente educadora. 4) La constante praxis educadora de la Iglesia en la historia de la evangelización. 5) Importancia de la educación en la doctrina eclesiológica del Concilio Vaticano II.
\end{abstract}

\section{Palabras clave}

Educación, didascalia, función esencial, Iglesia, normativa pastoral.

\begin{abstract}
The following issues are dealt with in order to demonstrate that didascalia (education of christians) is a forgotten essential function of the Church in today pastoral rules: 1) underestimation of the educative function of the Church in today pastoral rules; 2) didascalia is an essential function of the Church in the biblical texts on her foundation. 3) Jesus Master founded an essentially educative Church. 4) The permanent educative praxis of the Church in the history of evangelization. 5) Importance of education in the ecclesiological doctrine of the Vatican II Council.

\section{KEY WORDS}

Education, didascalia, essential function, Church, pastoral rules.
\end{abstract}


Enrique García Ahumada, F.S.C. | La Didascalia, olvidada función esencial DE LA IgLesia

\section{Minusvaloración de la función educativa DE LA IGLESIA EN LA NORMATIVA PASTORAL ACTUAL}

Al reflexionar respecto de la teología de la educación, se nota ausencia de la educación entre las funciones esenciales de la Iglesia en la normativa pastoral actual (García 2016, 61). Inversamente, San Juan Bautista De La Salle, Patrono universal de los educadores proclamado en 1950 por el Venerable Pío XII y pionero de la teología de la educación (García, 2013), plantea la educación cristiana como función esencial de la Iglesia. Lo manifiesta en sus Meditaciones para los días de retiro para cuantas personas se dedican a la educación de la juventud, y particularmente para el retiro que los Hermanos de las Escuelas Cristianas tienen durante las vacaciones (De La Salle 2001, I, 577-621). Vincula allí a la educación contextos bíblicos claves: Rm 10, 14-15; 11, 13-14; 12, 6-8; 1 Cor 1, 17; 3, 9-10; 4, 1; 2 Cor 4, 1-2. 6; $1 \mathrm{Tm}$ 2, 4. En sus demás Meditaciones ${ }^{9}$ destaca la predilección por la educación y la catequesis en santos apostólicos: María Santísima (M 151), San José (M 110), San Joaquín (M 157), Santa Ana (M 146), Santa Mónica (M 122), Santa Margarita de Escocia (M 133), San Cayetano (M 153), San Pedro (M 139), San Pablo (M 140), San Andrés (M 78), San Juan (M 88), Santiago el Mayor (M 145), San Felipe (M 119), San Mateo (M 167), San Bartolomé (M 159), Santo Tomás (M 84), San Simón y San Judas (M 182), San Matías (M 107); en los Padres de la Iglesia de Oriente San Atanasio (M 120), San Basilio (M 136), San Gregorio Nacianceno (M 126) y San Juan Crisóstomo (M 100) y de Occidente San Ambrosio (M 81), San Jerónimo (M 170), San Agustín (M 161), San Gregorio I papa (M 109); en los misioneros San Juan el Bautista (M 138), San Marcos (M 116), San Lucas (M 178), San Bernabé (M 134), San Yon (M 168), Santo Domingo (M 150), San Francisco (M 173), San Ignacio de Loyola (M 148), San Francisco Javier (M 79), San Pedro de Verona (M 117); en los obispos San Ignacio de Antioquía (M 102), San León 
Magno (M 114), San Antonio, abad (M 97), San Marcelo (M 186), San Cipriano (M 166), San Paulino de Nola (M 137), San Nicolás de Mira (M 80), San Remigio (M 171), San Martín de Tours (M 189), San Sulpicio (M 98), San Germán (M 131), San Norberto (M 132), San Dionisio (M 175), San Román (M 181); en los maestros San Casiano (M 155), San Anselmo (M 115), San Bernardo (M 158), Santo Tomás de Aquino (M 108), San Buenaventura (M 142), San Benito (M 111), Santa Catalina de Siena (M 192), San Bruno (M 174), San Francisco de Paula (M 113), San Bernardino de Siena (M 128), San Antonio de Padua (M 135), San Carlos Borromeo (M 187), San Francisco de Sales (M 101) San Esteban diácono (M 87).

Extrańamente, la normativa pastoral actual no considera esencial en la Iglesia su función educativa. En los ritos del Bautismo y de Confirmación, se invoca al incorporar en la Iglesia a quienes se unge con el santo crisma: "Dios todopoderoso, Padre de nuestro Señor Jesucristo, que les has dado nueva vida por el agua y el Espíritu Santo, y les has concedido el perdón de todos los pecados, les unge con el crisma de la salvación, para que, incorporados a su pueblo santo, permanezcan como miembros de Cristo sacerdote, profeta y rey hasta la vida eterna". No menciona el rol educador conferido a cada cristiano.

Emilio Álberich, ex Presidente de la Asociación Española de Catequetas y del Grupo Europeo de Catequetas, argumenta en su muy traducido manual de catequética (Alberich 1983):

"Tradicionalmente, tanto la teología pastoral como la praxis eclesial -y el mismo Concilio- han presentado las funciones eclesiales según el esquema tripartito del triple oficio de Cristo sacerdote, profeta y rey, distinguiendo así un triple ministerio en la Iglesia: litúrgico, profético y real".

No parece, empero, que esta división tenga un fundamento del todo convincente, ni que resulte adecuada a las reales articulaciones del quehacer eclesial, especialmente por lo que se refiere a la función 
llamada 'real' (Rahner en Arnold, 1970, pp. 233-236) ${ }^{10}$. En cambio, parece más convincente y adecuada una división cuatripartita, que puede apoyarse en la naturaleza sacramental de la Iglesia en cuanto signo e instrumento del Reino de Dios. El ideal del Reino, del que la Iglesia constituye un germen y un comienzo, se hace presente y visible en el mundo en cuatro formas fundamentales de presencia eclesial: como Reino realizado en el amor y en el servicio fraterno (signo de la Diaconía); como Reino vivido en la fraternidad y en la comunión (signo de la Koinonía); como Reino proclamado en el anuncio liberador y significante del Evangelio (signo del Kerygma); como Reino celebrado en los ritos festivos y liberadores de la liturgia (signo de la Liturgia)"11.

Tampoco este esquema cuatripartito menciona a la educación como signo importante de la presencia del Reino de Dios en el mundo. En la siguiente versión de 1991 de su manual, al situar la catequesis en la evangelización y en el ministerio de la Palabra, la vincula con "la profecía, que estimula a la comunidad a discernir la voluntad de Dios en la historia” (Alberich, 1991, p. 47), primera función sustitutiva de la que antes llamó kerygma. Sus últimos tres capítulos son: 6: Catequesis, caridad y compromiso (cuyo párrafo central es "Catequesis y diaconía eclesial"); 7: Catequesis, comunión y comunidad, donde repite la palabra koinonía, y 8: Catequesis y liturgia, que completa el cuarteto.

En su última versión de 2003 considera aceptado el conjunto articulado de la acción evangelizadora de la Iglesia mediante las siguientes funciones, en que el proyecto del Reino en su visibilidad se realiza en Diaconía (amor-caridad, servicio, promoción, educación, liberación, solidaridad); se vive en Koinonia (comunión, fraternidad, reconciliación, unidad, comunicación, comunidad); se proclama en

10 Karl Rahner enumera seis funciones fundamentales de la Iglesia: evangelización, culto, administración de los sacramentos, vida jurídica, vida cristiana y acción caritativa. (Nota de Álberich).

11 El cuádruple signo consta ya de algún modo en el famoso sumario de Lucas sobre la comunidad primitiva (Hch 2, 42-47). (Nota de Álberich) 
Martyría (anuncio, testimonio, profecía, catequesis, predicación); y se celebra en Liturgia (eucaristía, sacramentos, celebración, fiestas, devociones, oración) (Alberich, 2003, pp. 29-30). La educación figura entre los servicios al mundo como educación general, no como educación cristiana en la Iglesia.

El Catecismo Católico para Adultos de la Conferencia Episcopal Alemana caracteriza la esencia de la Iglesia como misterio, pueblo de Dios, cuerpo de Cristo que "participa de Jesucristo de un modo triple: participa en su función profética, en su función sacerdotal y en su función pastoral" (Conferencia Episcopal Alemana 1992, p. 301). De paso dice que la iglesia primitiva incorporó a los carismas los ministerios fundamentales e indispensables de los apóstoles, profetas y doctores (cf. 1 Cor 12, 28), y consideró a "los apóstoles, profetas, evangelistas, pastores y doctores" como dones del Señor resucitado a su Iglesia (cf. Ef 4, 11) (Conferencia Episcopal Alemana 1992, p. 304). Termina declarando propiedades esenciales de la Iglesia: ser una, santa, católica y apostólica (Conferencia Episcopal Alemana 1992, p. 305). Cuando menciona la apostolicidad de la Iglesia citando Mt 28, 18-20, trata la transmisión de la misión apostólica a los obispos (Conferencia Episcopal Alemana, 1992, pp. 315-319), sin mencionar a la educación.

La Comisión Nacional Francesa de Catequesis en Catecumenado de adultos describe en forma atrayente la comunidad convocada por Jesús: "En los Evangelios, la Iglesia es el grupo de discípulos que hacen vida común con Jesús, tienen derecho a una enseñanza particular (Mc 4, 33-34) y colaboran en el apostolado del Maestro" (Lc 10, 1). Jesús los va educando poco a poco en las costumbres del Evangelio: Orar al Padre con confianza, darse totalmente a la causa del Reino de Dios, servir en lugar de aprovecharse, perdonarse unos a otros, ir en busca de la oveja perdida, contentarse con lo que se tiene, afrontar animosamente las contradicciones" (Comisión Nacional Francesa de Catequesis 1996, p. 220). Después afirma: "la vida de los cristianos en la Iglesia se resume en cuatro rasgos esenciales: 'Eran asiduos en escuchar la enseñanza de los apóstoles, en la solidaridad 
Enrique García Ahumada, F.S.C. | La Didascalia, olvidada función esencial DE LA IgLesia

[el buen entendimiento y el apoyo mutuo], la fracción del pan [la eucaristía] y las oraciones [en común]" (Hechos 2, 42)" (Comisión Nacional Francesa de Catequesis, 1996, p. 222). Un párrafo posterior sólo describe y define "la Iglesia una, santa, católica y apostólica" (Comisión Nacional Francesa de Catequesis 1996, pp. 225-226). Este documento elaborado por catequistas de catecumenado da importancia a Jesús Maestro y a la educación, pero no sistematiza las funciones básicas de la Iglesia.

\section{LA DIDASCALIA ES FUNCIÓN ESENCIAL DE LA IGLESIA EN LOS TEXTOS BÍBLICOS SOBRE SU FUNDACIÓN}

"Profecía" difiere en la Biblia de "magisterio" o "enseñanza". Jesús "dispuso que unos fueran apóstoles, otros, profetas; otros, evangelizadores; otros, pastores y maestros" (Ef 4, 11). "Dios puso en la Iglesia primero apóstoles; en segundo lugar, profetas; en tercer lugar, maestros; luego, los milagros; después, el don de curaciones, de asistencia, de gobierno, diversidad de lenguas" (1 Cor 12, 28). Entre los principales ministros constructores de la Iglesia está el didáskalos, traducido a veces por "doctor" en el sentido de docente, o por "maestro", que es un formador de cristianos (ver Hch 13, 1; 1 Cor 12, 28; 14, 19). En ambos textos paulinos la didascalia es una de las funciones principales en la Iglesia.

Jesucristo en su último acto fundacional de la Iglesia le definió su misión al enviar a los apóstoles: "Id, pues, y haced discípulos a todas las gentes, bautizándolas en el nombre del Padre y del Hijo y del Espíritu Santo, y enseñándoles a guardar todo lo que yo os he mandado" (Mt 28, 18-20). Incluye dos tareas educativas: hacer discípulos y enseñar a guardar todo lo mandado. La Vulgata latina en vez de "hacer discípulos" (mazeteúsate) tradujo docete, enseñad, que se ha entendido reductivamente como transmitir la verdad revelada. Más amplio es educar, o conducir a la virtud (ver Os 11, 1-4), y a la santidad (ver Lev 11, 44-45, 1 Pe 1, 16; 1 Jn 3, 3), distinción muy 
importante. Todo cristiano tiene la misión de educar en su doble tarea, en lo positivo, de inspirar virtudes conducentes a la santidad con su vida y con su palabra estimulante de discípulo de Jesús (ver Col 3, 16; Heb 10, 24-25), y, además, en la tarea de enmendar lo negativo con la corrección fraterna (ver Mt 18, 15; Ga 2, 14; 6, 1-2). Sólo las autoridades de la Iglesia, que son Pedro y sus sucesores (ver Lc 22, 32), y los obispos en comunión con ellos, tienen la misión de enseñar, entendida como transmitir el depósito de la Palabra de Dios contenida en la Biblia y en la Tradición apostólica (ver 1 Tim 4, 6; 6, 20; 2 Tim 1, 13-14).

La síntesis más amplia de la vida de la primera comunidad cristiana de Jerusalén, reconocida descriptora de los rasgos esenciales de la Iglesia, declara:

"Se mantenían constantes en la enseñanza de los apóstoles, en la comunión, en la fracción del pan y en las oraciones. Pero el temor se apoderaba de todos, pues los apóstoles realizaban muchos prodigios y signos. Todos los creyentes estaban de acuerdo y tenían todo en común; vendían sus posesiones y sus bienes y repartían el importe de las ventas entre todos, según la necesidad de cada uno. Acudían diariamente al Templo con perseverancia y con un mismo espíritu; partían el pan en las casas y tomaban el alimento con alegría y sencillez de corazón, alabando a Dios y gozando de la simpatía de todo el pueblo. Por lo demás, el Seńor agregaba al grupo a los que cada día se iban salvando" (Hch 2, 42-47).

Muestra cuatro funciones esenciales de la Iglesia, que evangeliza y atrae por su testimonio de koinonía, liturgia y diaconía ya explicadas, y didascalia. Ésta abarca, a su vez, cuatro tareas educativas habituales en la Iglesia.

- La primera es el Magisterio doctrinal de Pedro y de los obispos en comunión con él acerca del depósito de la revelación o Palabra de Dios. Este magisterio eclesial se cumplió después del Concilio de Jerusalén en que "los apóstoles y presbíteros, de acuerdo con toda la iglesia” enviaron a Pablo, Bernabé, Judas 
Barsabás y Silas a explicar en persona y mediante carta la sana doctrina acordada "a los hermanos venidos de la gentilidad que están en Antioquía, en Siria y en Cilicia” (ver Hch 11, 19-25).

- Segunda forma de didascalia es la catequesis o educación para la vida cristiana, transmitida por Jesucristo y los apóstoles y después por los cristianos a los otros que surgían.

- La tercera es la mencionada educación mutua de los cristianos por el ejemplo y la palabra en lo positivo, y por la corrección fraterna ante lo negativo.

- Finalmente, la cuarta es la educación escolar, realizada en la Iglesia desde el principio, para apartar a los niños de la idolatría practicada en las escuelas imperiales durante las persecuciones romanas, como se verá luego.

\section{Jesús Maestro funda la Iglesia esencialmente EDUCADORA}

La propuesta eclesiológica de considerar la didascalia como función esencial de la Iglesia tiene fundamento cristológico, con rica base bíblica. Lucas presenta al Mesías anunciado como quien "bizo y enseñó" (Hch 1, 1). Jesús fue maestro reconocido desde el comienzo de su vida pública (ver Jn 1, 35-39). Él mismo usó ese título (ver Mc 14, 13-14; Mt 23, 8.10). Su rol de maestro es el mencionado con más frecuencia y pormenores en los Evangelios, como veremos, agrupando sus rasgos de maestro alrededor de algunos que lo caracterizan:

3.1. Jesús Maestro es la Palabra de Dios hecha hombre para dar sabiduría y salvación. Él afirmó a su juez Pilatos que formar discípulos fue su meta (ver Jn 18, 37). Explicó al justo magistrado fariseo Nicodemo su envío para la salvación en un versículo que, según opino, resume la Biblia y el plan de Dios: "Tanto amó Dios al mundo que dio a su 
Hijo unigénito, para que todo el que crea en Él no perezca, sino que tenga vida eterna" (Jn 3, 16).

3.2. Jesús Maestro es testigo de Dios. Dice: "Yo hablo lo que he visto junto a mi Padre... os he dicho la verdad que he oído de Dios" (Jn 8, 38.40; ver Mt 11, 27). Promete experiencia similar a Natanael y demás discípulos (ver Jn 1, 51). Dice vivir en compañía de Dios (ver Jn 8, 29). Dedica tiempos a orar solo (ver Mc 1, 35-37; 6, 46; Lc 5, 16; 6, 12; 9, 18.28-36). Los testigos de su comunión con Dios la extienden para alegrar a otros (ver 1 Jn 1, 1-4).

3.3. Jesús Maestro, mediante sus discípulos, extiende la bondad de Dios. Juan Bautista dijo: "Y la Palabra se hizo carne y puso su morada entre nosotros; y hemos contemplado su gloria, gloria que recibe del Padre como Unigénito, lleno de gracia y de verdad" (Jn 1, 14). Opino que muy poco se usa el texto básico sobre la gloria de Dios: "Moisés dijo a Yahvé: 'Déjame ver tu gloria'. Él le contestó: 'Yo haré pasar ante tu vista toda mi bondad" (Ex 33, 18-19). Santo Tomás de Aquino concluye: "La gloria de Dios es la manifestación de su bondad" (Suma de Teología, I Parte, cuestión 65, artículo 2). Jesús dice: "Brille así vuestra luz delante de los hombres, para que vean vuestras buenas obras y alaben a vuestro Padre que está en los cielos" (Mt 5, 16; ver Jn 15, 8).

3.4. Jesús Maestro ama a cada discípulo y lo conoce por su nombre. Dice: "Yo soy el buen pastor, conozco a mis ovejas" (Jn 10, 14), "a cada una por su nombre" (Jn 10, 3). Dinamiza a sus discípulos con el amor de darse enteros (ver Jn 15, 9-15). Todos sus discípulos educadores sobresalientes centran su enseñanza en el amor (García 2007, 4 vols.). 
Enrique García Ahumada, F.S.C. | La didascalia, olvidada función esencial DE LA IgLesia

3.5. Jesús Maestro da alegría. Su discurso inaugural comienza con bienaventuranzas (ver Mt 5,3-12). En la última cena reitera su afán de alegrar (ver Jn 15, 11; 16, 22).

3.6. Jesús Maestro no suprime el sufrimiento ni lo oculta a sus discípulos, pero le da sentido. "El que ama a su padre o a su madre más que a mí, no es digno de mí; el que ama a su hijo o a su hija más que a mí, no es digno de mí. El que no tome su cruz y me siga, no es digno de mí" (Mt 10, 37-38; ver Mc 8, 34-35). Enseña la gratitud para con Dios (ver Lc 17, 11-19). Se resigna a la ingratitud (ver Mt 26, 47-50), y prepara a sus discípulos a padecerla (ver Lc 6, 35 ver Jn 16, 2-4). Los anima a sufrir por la Buena Nueva del Reino de Dios (ver Mt 5, 11-12; Jn 15, 18.20; 16, 33).

3.7. Jesús Maestro centra su enseñanza en dejar el pecado para que en cada uno reine Dios: "Comenzó Jesús a predicar y a decir: “Convertíos, porque el Reino de los Cielos ha llegado" (Mt 4, 17). Toda su enseñanza es el Reino de Dios (ver Hch 1, 3). Exhorta a tener una sola meta en el mundo: "Buscad primero el reino de Dios y su justicia, y todas esas cosas se os darán por añadidura” (Mt 6, 33).

3.8. Jesús Maestro es liberador, como caracterizó su misión el profeta Isaías (ver Lc 4, 16-22), y Él lo declaró enfáticamente (Jn 8, 31).

3.9. Jesús Maestro ahonda la enseñanza de la Biblia. Declara que las Escrituras afirman ser Él quien da vida eterna (ver Jn 5, 39-40). Promete gran premio por cumplirla y enseñarla (ver Mt 5, 19s). Reprueba a quienes la exigen sin cumplirla (ver Lc 11, 46). Destaca textos bíblicos postergados (ver Mt 23, 23). Resume la moral de la Biblia en la regla de oro (ver Mt 7, 12). Exige conocer bien las Sagradas Escrituras (ver Mt 22, 29; Lc 24, 25-27). Corrige una concesión de 
Moisés (ver Mt 19, 8-9). Valora la misericordia con hombres y animales más que el descanso del sábado (ver Mt 12, 10b--12). Declara acatar las Escrituras y llevarlas a sus últimas consecuencias (ver Mt 5, 17-18). Perfecciona las Escrituras (ver Mt 5, 21-24.27-28.43-45). Emplaza a encontrar el sentido de un texto metafórico (ver Jn 10, 31-36). Se declara Señor del sábado (ver Mt 12, 8), superior al Templo (ver Mt 12,6 ), a Jonás (ver Mt 12, 41), a Salomón (ver Mt 12, 42), a David (ver Mt 22, 41-46), a Jacob (ver Jn 4, 12), y a Abraham (ver Jn 8, 53).

3.10. Jesús Maestro acompaña al formar discípulos. Compadece a la gente carente de guía (ver Mt 9, 36). Interesa a otros por aumentar los operarios dedicados a los demás (ver Mt 9, 36-37). Es aceptado porque sólo busca agradar a Dios (ver Jn 8, 27b-30). Elige colaboradores (ver Mc 3, 13; Jn 15, 16-17). Los llama personalmente (ver Mt 4, 18-22; 9, 9; 19, 21). Acepta a quienes por propia iniciativa lo siguen (ver Mt 20, 34), incluidas mujeres (Lc 8, 1-3). Encamina a otros según sus dotes (ver Mc 5, 18-20). Llama a personas de toda condición y mentalidad (ver Mt 4, 18-22; 9, 9; 10, 4). Les exige desprendimiento (ver Lc 9, 57-60; Mt 10, 37-39), prontitud (ver Lc 9, 61-62), autodominio (ver Mt 5, 11-12), autenticidad (ver Mt 5, 13), servir por gratitud (ver Mt 10, 8), prudencia (ver Mt 10, 16-18), confianza en el Espíritu Santo (ver Mt 10, 19-20), perseverancia (ver Mt 10, 22), y capacidad de organizar (ver Mt 13, 44-45; 15, 32-38). Los hace críticos de las opiniones ajenas (ver Mt 16, 13-17). Entrega responsabilidades gradualmente:

- Primero dar un bautizo similar al de Juan (ver Jn 3, 22; 4, $1-3)$.

- Luego elige doce para predicar y sanar (ver Lc 9, 1-2).

- Envía otros setenta y dos en parejas a una predicación preparatoria (ver Lc 10, 1).

- Va delante de sus discípulos, los guía con su voz (ver Jn 10, 4). 
Enrique García Ahumada, F.S.C. | La DidasCalia, olvidada función esencial DE LA IgLesia

- Pone a prueba a algunos que quieren seguirlo (ver Mt 8, 19-22; Lc 9, 60).

- Usa su autoridad para servir (Jn 13, 2-15).

- Valora la autoridad legítima de otros (ver Mt 8, 4; 23, 1-3) y la de buenos discípulos sin ser del grupo cercano (ver Lc 9 , 49-50).

- Rehúsa intervenir en lo que no le compete (ver Lc 12, 13-14).

- Soporta la rebeldía contra él como hombre, no la rebeldía contumaz contra el Espíritu Santo (ver Mt 12, 31-32).

- Concede a algunos oportunidades particulares (ver Mt 17, $1-8 ; 26,36-46)$.

- Los mantiene cerca para dedicarles tiempo preferente (ver Mc 4, 10-11; 9, 33-35; Mt 13, 36-43; 20, 17-19; Jn 4, 31-38; 6, 67-71; 11, 6-44 13, 2 - 17, 26).

- Da la vida por ellos (ver Jn 10, 14-18). Los acompaña después de resucitar (Hch 1, 3-9).

- Finalmente se retira y entrega total responsabilidad, aunque mantiene su compañía espiritual hasta el fin del mundo (ver $28,18-20)$.

3.11. Jesús Maestro enseña con múltiples recursos. Forma la voluntad en cumplir la de Dios (ver Mt 7, 21). Pone de modelo a Dios en su amor compasivo (ver Mt 5, 48; Lc 6, 36). Estimula con promesas espirituales (ver Mt 7, 11; 10, 40-42; Lc 10, 20) y terrenales (ver Mt 19, 29). Usa medios visuales (ver Mt 18, 1-4; 22, 15-21). Sostiene que acoger un niño es recibirlo a él (ver Mt 18, 5); dice que dar mal ejemplo o pervertir a un niño merece máximo castigo (ver Mt 18, 6); plantea que el niño es altamente respetable (ver Mt 18, 10) y ejemplo de sencillez para recibir el reino de Dios (ver Lc 18, 15). Prohíbe que les impidan acercarse a Dios (ver Mt 19, 13-15). Acaricia y bendice a los niños (ver Mc 10,16), y atiende sus necesidades, pero los devuelve a sus padres (ver Lc 9, 38-43). Promueve la familia mediante la monogamia (ver Mt 19, 4-9), la fidelidad (ver Mt 5, 27-28), y la tolerancia mutua (ver Mt 5, 31s); pero subordina las relaciones familiares a la unión 
con Dios (ver Mt 10, 37) y a cumplir su voluntad (ver Mt 12, 47-50). Interpela según la idiosincrasia de las personas (ver Mt 12, 22-28; 21, 23-27) y de los grupos (ver Mt 23, 16-22).

También repite refranes populares (ver Lc 17, 37), y observaciones corrientes sin sentar doctrina ni profetizar (ver Mc 6, 4; Mt 26, 52). Prefiere el lenguaje directo (ver Mt 5, 37). Usa figuras de lenguaje amenas y entendibles (ver Mt 6, 3; 7, 6; 16, 26; 17, 10-13), dichos enigmáticos (ver Mt 16, 5-12; 16, 24; Lc 14, 26; 22, 35-38; 23, 2631; Jn 2, 18-22; 3, 3-8.14-15; 16, 25), contrastes impactantes (ver Mt 12, 38-42; 16, 25; 21, 31-32), exageraciones impresionantes (ver Mt 5, 29-30.39-41.48; 8, 22; 13, 31-32; 17, 20; 18, 8-9.21-22; 19, $24 ; 23,24)$ y la ironía (ver Jn 3, 10; 7, 28-29; 13, 38).

Además, expresa hechos mentales en imágenes sensibles (ver Mt 6, 2.5.16-17; 7, 13-15; 13, 19-23). Hace pensar mediante muchas preguntas (ver Mt 5, 46-47; 6, 25-31; 7, 3-4.9-10.16; 9, 4-5; 11, 7-9; 12, 26-27.29; 16, 8-11; 22, 41-45). Educa la capacidad crítica y da criterios de discernimiento (ver Mt 7, 15-20). Ayuda a distinguir la apariencia de la realidad (ver Jn 7, 24), el aprecio de los hombres y el de Dios (ver Lc 16, 15). Al criticar señala en qué mejorar (ver Mt 12, 24-28; 22, 1-14.15-21). Rechaza la despreocupación por los pobres y el afán de alabanzas humanas (ver Lc 6, 24-26), y obrar mal o mover al mal a otros (ver Mt 18,7). Conduce el diálogo hacia lo importante (ver Mt 19, 17; 22, 41-46; Jn 4, 7-26). Emplea el humor (Mt 7, 3.6.19; Mc 10, 25 en Gruen, 2015, 353, nota 34). Da enseñanzas ocasionales a partir de hechos (ver Mt 12, 1-8.46-50; 17, 24-27; 22, 19-21; 24, 1-2; Lc 13, 1-4; 21, 1-4). Transmite verdades con experiencias impactantes (ver Mt 17, 1-9; Lc 8, 23-25; 14, 1-6; Jn 13, 3-15). Discute para salvar a sus interlocutores (ver Jn 5, 34).

No es siempre afectuoso al comunicarse, consciente de su misión de Dios Padre que cumple con todas sus exigencias ante cualquier persona, incluso pobres, enfermos o sus padres (Silva 2009: III, 308-310). Respeta la libertad de cada uno (ver Lc 9, 51-56) pero deja en claro las responsabilidades (ver Lc 10, 10-12.16). Defiende 
Enrique García Ahumada, F.S.C. | La Didascalia, olvidada función esencial DE LA IgLesia

las cosas de Dios (ver Mt 21, 12-13). Evalúa logros y no logros (ver Lc 9, 18-21; 10, 17-24).

3.12. Jesús Maestro santifica mediante sacramentos. Cambió la antigua transmisión de la fe por relato oral o por lectura familiar o en asamblea de la Sagrada Escritura, para explicarla y orar. Creó un cambio que encierra un misterio, como hizo notar a Nicodemo: "En verdad, en verdad te digo que el que no nazca de agua y de Espíritu no puede entrar en el Reino de Dios" (Jn 3, 1- 5). Alude a una novedad en el bautismo por acción del Espíritu Santo. Comenzó su ministerio público recibiendo de Juan el bautismo en que los evangelistas lo presentan en el centro del misterio trinitario (ver Mt 3, 13-17; Mc 1, 9-11; Lc 3, 21-22; Jn 1, 29-34). Lo culminó en su última cena instituyendo los sacramentos de eucaristía y sacerdocio de la Nueva Alianza que se ejercería en memoria suya (ver 1 Cor 11, 24b). Allí enseñó por primera vez sobre el Espíritu Santo que además prometió como fuente de su comunión (ver Jn 14, 15-17.25-26).

La segunda carta de Pedro afirma que la extraordinaria comunión a que Dios nos llama consiste en participar de la naturaleza divina (ver 2 Pe 1, 2-4). Es misteriosa divinización o santificación del ser humano. La tarde del domingo de resurrección Jesús confirió a los Apóstoles el ministerio de perdonar pecadores (ver Jn 20, 19-23). Antes de su Ascensión los envió diciendo:

"Me ha sido dado todo poder en el cielo y en la tierra. Id, pues, y haced discípulos a todas las gentes, bautizándolas en el nombre del Padre y del Hijo y del Espíritu Santo, y enseñándoles a guardar todo lo que yo os he mandado. Y estad seguros que yo estaré con vosotros día tras día, hasta el fin del mundo" (Mt 28, 18-20).

Manda difundir con el bautismo - distinto del de Juan- la comunión del Padre, el Hijo y el Espíritu Santo, prometida hasta el fin del mundo. San Juan la expresa como llegar a ser hijos de Dios (ver 1 Jn 3, 1). Jesús había dicho: "Comprenderéis que yo estoy en mi Padre y 
vosotros en mí y yo en vosotros" (Jn 14, 20. 23). Ese cambio confiere fecundidad para extender el reino de Dios (ver Jn 15, 5.11.26-27).

Transmitir la fe cristiana implica santificar la persona. Jesús, para santificar, crea el nuevo bautismo y demás sacramentos. San Pablo se asombra (ver Ef 3, 14-17.19). El bautizado gana grandeza aún en su cuerpo (ver 1 Cor 6, 19). Al explicar el matrimonio cristiano, después de decir: "Maridos, amad a vuestras mujeres como Cristo amó a la Iglesia y se entregó por ella" (Ef 5, 25), dice: "Gran misterio es éste, lo digo respecto a Cristo y a la Iglesia" (Ef 5, 32). Santiago exhorta a la práctica sacramental (ver St 5, 14-16). La vida nueva a que conduce Jesús Maestro es santificada por el Espíritu Santo mediante los sacramentos. Agradecidos los fieles celebramos en comunidad la eucaristía, al menos en domingo, en memoria de la Pascua de Resurrección.

\section{LA CONSTANTE PRAXIS EDUCADORA DE LA IGLESIA EN LA HISTORIA DE LA EVANGELIZACIÓN.}

La Iglesia desde el comienzo mantuvo dos didascalias permanentes: la educación escolar y la catequesis. Antes del primer emperador romano hecho cristiano, Constantino (g. 306-337), las primeras personas con consagración especial posterior a la del bautismo, fueron vírgenes dedicadas en sus casas a educar niños para evitar la idolatría obligatoria en las escuelas imperiales. Lo atestigua San Antonio Abad (c. 250-17.1.356), padre del monaquismo, que hacia los 18 años quedó heredero con una hermana menor, cuya educación al partir al desierto encomendó a unas vírgenes que vivían consagradas en sus familias jantes que los varones! (Atanasio, 1995, 35-36), de cuya importante acción misionera al menos entre los siglos II y IV informa San Metodio mártir (Vizmanos, 1949, p. 137).

¿Cómo empezó el catecumenado? Según el Manual de disciplina encontrado entre los manuscritos de cuevas junto al mar Muerto en 1948, una comunidad selecta, identificada sin fundamento con los 
Enrique García Ahumada, F.S.C. | La Didascalia, olvidada función esencial DE LA Iglesia

esenios hasta la interpretación de esos manuscritos por André Paul (Paul, 2009), exigía para ingresar un juramento, postulantado de un año con etapas rigurosas de instrucciones y ayunos, a cargo de un responsable que daba cuenta a la comunidad sobre sus aptitudes y cumplimiento, y votada la admisión había noviciado de dos años. Entonces profundizaban la fe en la Alianza, participaban en el baño diario de purificación, pero no en la comida sucesiva a mediodía hasta su ingreso definitivo en la comunidad (Floristán, 1989, pp. 46-47).

Los cristianos imitaron en el catecumenado este proceso preparatorio, quizá no exclusivo de dicha comunidad judía. Los paganos, atraídos por la elevación moral de Israel, valoraron en los cristianos no tener ritos chocantes como la circuncisión, ni necesidad de ser leales a otra nación, ni diferenciarse respecto de los demás creyentes. Eso explica la pronta aceptación a San Pablo en sinagogas de la diáspora como Antioquía de Pisidia (ver Hch 13, 16.43) o Filipos de Macedonia (ver Hch 16, 14s), y aclara el furor de los judíos en Tesalónica (ver Hch 17, 1-8), y en Corinto (ver Hch 18, 5-17), al ver hacerse cristianos a quienes estaban por hacerse judíos o lo eran. Consta el catecumenado en la época apostólica, pues San Pablo ordena: "Que el catecúmeno comparta sus bienes con el catequista" (Ga 6, 5).

Los Padres Apostólicos San Clemente I de Roma (n. 35), San Ignacio Obispo de Antioquía (+108) y San Policarpo de Esmirna (+155), fueron educadores, obispos, misioneros, catequistas y teólogos. San Justino de Naplusa (+c.165), y otros apologistas, con su enseñanza académica encaminaron a la fe. Panteno de Sicilia (+c.200), después de misionar en la India, volcó a formar catequistas en Alejandría, en la escuela llamada Didascaleo, donde su sucesor, que sobre él nos informa, Clemente de Alejandría (c.150-215), organizó la evangelización en tres etapas después normativas: la misión en su Protréptico (Clemente 2008), la catequesis en El Pedagogo (Clemente 1994) y la educación a la vida cristiana en Strómata (Clemente 1996).

Desde Constantino, la escuela pública formó cristianos, y el bautismo de niños sustituyó gradualmente al catecumenado de adultos. El papa Sixto II (g. 257-258), en su Liber Pontificalis organizó 
la formación de los niños de los coros parroquiales, que el papa San Zócimo (g. 417-426), amplió más allá de la sola liturgia. Numerosos santos medievales fueron educadores. San Mesrop Vartapet (345440), con el patriarca San Sahak el Grande (+439), inventaron el alfabeto armenio, tradujeron la Biblia y los escritos patrísticos, y crearon monasterios donde cada clérigo bien formado era vartapet, educador. San Cesáreo de Arles (+542), impulsó escuelas parroquiales.

Sirvieron en la Iglesia los maestros Boecio (480-525), Casiodoro (485-580), San Isidoro de Sevilla (c.560-636), San Alfredo el Grande rey de Wessex (849-899), el papa Silvestre II (g. 999-100), impulsor de la escuela municipal y de los estudios clericales. El papa San Gregorio VII (c. 1020-1085); Hugo de San Víctor (1096-1141), autor del tratado de educación Eruditionis Didascalia; Vicente de Beauvais, O.P. (1190-1264), autor de la mayor enciclopedia medieval Speculum maius; Radulfo Ardens (+1200), educador de virtudes intelectuales y afectivas; San Buenaventura, O.F.M. (1221-1274), autor de Jesús Maestro; Gilberto de Tournai, O.F.M. (+1288), autor de la enciclopedia Rudimentum doctrinae christianae; San Raimundo Lulio (1233-1315), autor de Doctrina pueril sobre la educación de sus hijos.

El Concilio III de Letrán en 1179 mandó a las catedrales mantener maestro para los pobres. La Beata María de Oignies (1177-1213), inició los beguinajes de educadoras no claustradas con votos privados. Escolarizaron a los pobres las órdenes mendicantes de Santo Domingo de Guzmán (1170-1221), San Francisco de Asís (1182-1226), y los Siete Santos Fundadores de los Siervos de María de 1233. El diácono Gerard Groot (1340-1384), inició los Hermanos y las Hermanas de la Vida Común como educadores cristianos.

En círculos eclesiales surgieron en Europa las universidades: el jurista Irnerio (1067-1125), generó la de Bolonia. En 1170 se formó la universidad de Oxford con ingleses emigrados del colegio catedralicio de París, cuya universitas magistrorum et scholarium reconoció el rey en 1180. Alfonso IX de Castilla fundó hacia 1218 la universidad de Salamanca, primera con ese nombre. El monasterio de Salerno inició un Studium Generale trasladado a Nápoles, hecho universidad estatal 
Enrique García Ahumada, F.S.C. | La DidasCalia, olvidada función esencial DE LA IgLesia

en 1224 por el emperador Federico II. En 1290 se fundó la Universidad de Coimbra en Portuga. en 1348 la de Praga en Bohemia. En 1364 la de Viena en Austria y la de Cracovia en Polonia. En 1385 la de Heidelberg en Alemania. En 1426 la de Lovaina en la Bélgica actual. En 1460 la de Basilea en Suiza. En 1477 la de Upsala en Suecia. En 1479 la de Copenhague en Dinamarca. Universidades extendidas por Espańa y luego a América.

Para la catequesis misionera fundaron monasterios evangelizadores en Armenia San Gregorio el Iluminador (+331); en Escocia San Niniano (c.360-432); en Irlanda San Patricio (c.390- c.461); en Italia Santa Paula la Mayor (347-404); en Israel su nieta Santa Paula la Joven (+440), Santa Escolástica de Nursia y su hermano San Benito (c.480543), San Sabas (+532), archimandrita de los anacoretas del desierto de Judá. En Luxeuil San Columbano (521-597); en Lindisfarne de Nordhumbría San Aidan (+651); Santa Hilda en Withby (+680); en Inglaterra San Beda de Jarrow el Venerable (672-735); en Alemania Rábano Mauro (c. 780-856). Santa Lioba de Wessex (+782), los hermanos San Cirilo (+869), y San Metodio evangelizaron a los eslavos de Asia y Europa en su lengua. Santa Hildegarda en Bingen (1098-1179). Guillermo el Piadoso (+918), duque de Aquitania creó del monasterio de Cluny, generador de cientos de filiales.

Entre 511 y 614 más de treinta sínodos diocesanos comenzaron a organizar la vida eclesial incluyendo una instrucción cristiana mínima obligatoria. Al reducirse la preparación bautismal a saber el credo, San Martín (c.510-572), obispo de Braga en Lusitania, Portugal actual, en 572 exigió tres semanas de preparación para explicar el Credo y agregó el Padre Nuestro. San Ildefonso de Toledo (607667), pidió explicar después del bautismo sus ceremonias, el Credo y el Padrenuestro. El sínodo de Cloveshow del 747 en Inglaterra fue modelo al prescribir a los sacerdotes el contenido de la instrucción cristiana en lengua materna: "Símbolo de la fe, Pater noster, rito de la santa misa y del bautismo y su significado espiritual" (Mansi 1960, XII, 387). Los sínodos alemanes de Francfort en 794, de Aquisgrán en 801 y los de Mons en Galia Bélgica y de Maguncia 
en 813 exigieron a los sacerdotes, maestros, padres y padrinos saber el Credo, el Padrenuestro y el Avemaría. Desde el siglo X agregan enseñanza moral basada en el Decálogo y en los que empiezan a llamarse Pecados Capitales, o impropiamente "Pecados Mortales".

El Beato Alcuino de York, desde 782 director de la Escuela Palatina, establecida por el emperador franco Carlomagno (742-814), en su capital Aquisgrán (Aachen), en la actual Alemania, suprimió la pena capital impuesta por Carlomagno a quien rechazara el bautismo, y exigió para bautizar una preparación de siete a cuarenta días, apoyándose en De catechizandis rudibus de San Agustín (Etchegaray 1968). Carlomagno mandó a todo obispado, monasterio y parroquia mantener una escuela para enseñar la doctrina cristiana, canto, lectura de los salmos y gramática (Eginardo 1999), y exigió a cada sacerdote enseñar el Credo y el Padrenuestro con "un completo estudio de la religión y del culto de la cristiandad” (Mansi 1960, XIII, col. 1093).

Los siete sacramentos, declarados por el Concilio Ecuménico de Lyon en 1275, se agregaron en los Países Bajos en los sínodos de Utrecht de 1294 y 1310. En 1322 el Concilio de Valladolid (Concilio de Valladolid, 2002), incluyó los artículos de la fe y los sacramentos, presentados como remedios; en la moral incluyó el Decálogo con los vicios capitales y virtudes, en un esquema expositivo sin preguntas y respuestas, para memorizar en los domingos de Cuaresma, en Navidad, Resurrección, Pentecostés y Asunción. El sínodo de Talavera de la Reina en 1498 estableció los cinco preceptos de la Iglesia, que agregan la vida sacramental (García, 1991, pp. 163-197).

Los humanistas católicos renacentistas renovaron la educación cristiana y la catequesis. El Pbro. Erasmo de Rotterdam (1466-1536) educó por el conocimiento de las cosas mismas y no sólo por libros. Volvió a las fuentes griegas de la Biblia, propuso traducir los Evangelios y epístolas para los sencillos e indígenas y creó un sistema de tres niveles: un catecismo menor, uno reflexivo para adolescentes y otro mayor para catequistas. El canciller inglés Santo Tomás Moro (14781535), inició para sus hijas y familiares la igualdad educativa para la 
Enrique García Ahumada, F.S.C. | La Didascalia, olvidada función esencial DE LA Iglesia

mujer. El español Juan Luis Vives (1492-1540) inició la psicología positiva y la psicología pedagógica.

Fundaron las primeras congregaciones docentes femeninas Santa Beatriz da Silva (1424-1490) llamada las Hermanas de la Inmaculada Concepción en Portugal, cuya Regla adoptaron terciarias franciscanas con monasterios en Bélgica; y Santa Angela Mérici (1474-1540), en 1535, funda la Compañía de Santa Úrsula de educadoras en monasterios.

Fundaron congregaciones masculinas docentes San Jerónimo Emiliani (1486-1538), como la Compañía de los Siervos de los Pobres, que por orden papal aceptaron pensionados de nobles; San Antonio Maria Zaccaria (1502-1539), fundó los Clérigos Regulares de San Pablo, llamados barnabitas, por la iglesia de San Bernabé con que comenzaron en Milán, abiertos a la educación por San Carlos Borromeo; San Ignacio de Loyola (1491-1566), los jesuitas aprobados en 1540, como Compañía de Jesús con Constituciones para predicar, dar lecciones públicas y catecismo; el metodólogo Beato César de Bus (1544-1607), funda la congregación de sacerdotes de la Doctrina Cristiana.

En el siglo XVII aumentaron las fundaciones docentes. Sólo en Francia se fundaron unas 180 instituciones femeninas, casi 150 dedicadas a San José, y los Hermanos de las Escuelas Cristianas, fundados por San Juan Bautista De La Salle, luego se extendieron a otros países. En el siglo XIX en reacción a las destrucciones de conventos durante la revolución francesa se fundaron tantas, que el $70 \%$ de los misioneros del mundo eran franceses. Entre 1914 y 1918, 63 de las 162 congregaciones femeninas en misiones eran francesas; de las masculinas no consta por su mezcla interna de nacionalidades (Arens 1921, 327). En el siglo XX surgieron muchas más en todo el mundo (Annuario Pontificio 2003, 1293-1569), formando un enorme contingente de servicio a la evangelización. 


\section{IMPORTANCiA DE LA EDUCACIÓN EN LA DOCTRINA EClesiológica del Concilio Vaticano II}

- La finalidad de la educación cristiana es la santidad (Constitución Lumen Gentium 40).

- La educación cristiana perfecciona la persona, construye la Iglesia y transforma la sociedad según el Evangelio (Declaración Gravissimum Educationis 2).

- El deber de educar compete primero a la familia, requiere la colaboración de toda la sociedad, y es propio de la Iglesia Madre para ofrecer a todos la salvación (Gravissimum Educationis 3).

- La Iglesia ha de ayudar a los alumnos de escuelas no católicas mediante el testimonio de vida y el apostolado de maestros, condiscípulos, sacerdotes y seglares, desde diversos auxilios espirituales (Gravissimum Educationis 7).

- La escuela católica se distingue por un ambiente de comunidad animado por el espíritu evangélico de libertad y de caridad, ayuda a cada persona a crecer según Jesucristo y a difundir el reino de Dios, e ilumina con la fe el conocimiento del mundo, de la vida y del hombre. La animan maestros dotados de ciencia profesional y religiosa que sean testigos de Cristo con su vida y su doctrina, unidos con los alumnos por la caridad, que colaboran con los padres de familia en apostolado muy necesario e importante servicio a la sociedad (Gravissimum Educationis 8ac).

- Pastores y fieles deben ayudar a las escuelas católicas, ante todo, a atender las necesidades de los pobres en bienes temporales, de los privados del auxilio de la familia o que no participan del don de la fe (Gravissimum Educationis 9c).

- La Iglesia atiende la educación superior, y en Universidades y Facultades que dependen de ella, procura que se cultive cada disciplina según sus propios principios y métodos con libertad 
de investigación científica, para mejorar su comprensión y la de la compatibilidad de la fe con la razón, conforme a los doctores de la Iglesia, principalmente Santo Tomás de Aquino. Procura que sus estudiantes sean prestigiosos por su doctrina, testigos de la fe y preparados para las más importantes funciones (Gravissimum Educationis 10).

- Dondequiera que Dios encuentre buena disposición, anúnciese al Dios vivo y a su enviado Jesucristo para salvar a todos, para que los no cristianos, por obra del Espíritu Santo, creyendo, se conviertan libremente al Señor y se unan sinceros a Él, quien colma sus exigencias espirituales. Esta conversión inicial permite emprender un camino espiritual en el catecumenado. La Iglesia prohíbe severamente obligar o inducir o atraer a nadie por medios indiscretos a abrazar la fe, y apartar de la fe con vejaciones y amenazas. Según su antiquísima costumbre, investíguense los motivos de la conversión y, si es necesario, purifíquense (Decreto Ad Gentes 13).

- Quienes han recibido de Dios mediante la Iglesia la fe en Cristo, admítanse en ceremonias litúrgicas al catecumenado, que no es mera exposición de dogmas y preceptos, sino formación y noviciado prolongado de toda la vida cristiana, con el que los discípulos se unen a Cristo, su Maestro. Iníciense en el misterio de la salvación, en practicar las costumbres evangélicas, los ritos sagrados sucesivos y la vida de fe, de la liturgia y de la caridad de la Iglesia. Liberados del poder de las tinieblas por los sacramentos de iniciación cristiana, y resucitados con Cristo, celebren el memorial de la Pascua del Señor. Es deseable que la liturgia cuaresmal y pascual los prepare a celebrar el misterio pascual en el bautismo. Toda la comunidad debe procurar la iniciación cristiana durante el catecumenado, para que desde el principio ellos se sientan pertenecientes al Pueblo de Dios, y aprendan a cooperar en la evangelización con el testimonio de la vida y la profesión de fe (Ad Gentes 14). 
- Restáurese el catecumenado de adultos, dividido en distintas etapas, santificado con los sagrados ritos celebrados en tiempos sucesivos, cuya práctica dependerá del juicio del Ordinario del Lugar (Constitución Sacrosanctum Concilium 64).

- El primero de los medios educativos de la Iglesia es la instrucción catequética, que ilumina y robustece la fe, nutre la vida con el espíritu de Cristo, conduce a una consciente y activa participación de la liturgia y excita a la acción apostólica (Gravissimum Educationis 4).

- Vigilen los obispos, para que se dé cuidadosa instrucción catequética fundada en las Sagradas Escrituras, en la Tradición, Liturgia, Magisterio y vida de la Iglesia, cuyo fin es que la fe, ilustrada por la doctrina, se torne viva, explícita y activa en los nińos, adolescentes y adultos; que al darla se observen el orden debido y el método acomodado a la materia, al carácter, aptitudes, edad y condiciones de vida de los oyentes. Cuiden la preparación de los catequistas para su función, con conocimiento claro de la doctrina de la Iglesia, y teórico y práctico de las leyes psicológicas y pedagógicas, y que se restablezca o se adapte mejor la instrucción de los catecúmenos (Decreto Christus Dominus 14).

\section{Conclusión}

La educación cristiana o didascalia, función minusvalorada en la normativa pastoral actual, es declarada función esencial de la Iglesia al fundarla Jesucristo y en la ejemplar comunidad primitiva de Jerusalén. Jesús, Maestro por excelencia, fundó la Iglesia educadora hacia la santidad. Lo confirma su constante experiencia histórica y lo enseña el Concilio Vaticano II. Por tanto, las normas pastorales deben actualizarse destacando la didascalia como función esencial de la Iglesia. 
Enrique García Ahumada, F.S.C. | La Didascalia, olvidada función esencial DE LA Iglesia

\section{REFERENCIAS BIBLIOGRÁFICAS}

Alberich Sotomayor, Emilio (2003). Catequesis evangelizadora. Manual de catequética fundamental. Quito, Ecuador: Abya-Yala.

La catequesis en la Iglesia (1991). Elementos de catequética fundamental. Madrid, España: Editorial CCS.

Catequesis y praxis eclesial. Identidad y dimensiones de la catequesis en la Iglesia de hoy (1983). Madrid, España: Central Catequística Salesiana.

Annuario Pontificio per l'anno 2003 (2003). Città del Vaticano, Librería Editrice Vaticana.

Aquino, Santo Tomás de (1965, c. 1270). Suma de teología. Madrid, España: BAC.

Arens, Bernard (1921). Handbuch der katholischen Missionen, Freiburg, Herder, recensionado por A. Brou, en Etudes 167, 326-344.

Atanasio. Vida de Antonio (1995). Madrid-Buenos Aires-BogotáSantiago, Ciudad Nueva.

Biblia de Jerusalén. Nueva edición totalmente revisada (2009). Bilbao, España: Desclée de Brouwer.

Clemente de Alejandría (2008, c.202). El Protréptico. Madrid-BogotáSantiago, Ciudad Nueva.

__-_-_ (1994, c.202). El Pedagogo. Madrid, Ciudad Nueva. (1996, c.202). Strómata. Madrid, Ciudad Nueva.

Comisión Nacional Francesa de Catequesis (1996). Catecumenado de adultos. Bilbao, España: Mensajero.

Concilio de Valladolid (2002, 1322). Texto en latín y castellano, "Itinerarium" 10. 
Concilio Vaticano II (1970). Constituciones. Decretos. Declaraciones. Legislación posconciliar. Madrid, España: Biblioteca de Autores Cristianos.

Conferencia Episcopal Alemana (1992). Catecismo Católico para Adultos. Madrid, España: Biblioteca de Autores Cristianos.

De La Salle, San Juan Bautista (2001). Obras completas, Madrid, España: Ediciones San Pío X, 3 vols.

Eginardo (1999). Vida de Carlomagno. Madrid, España: Gredos.

Etchegaray Cruz, SS.CC., A. (1968). Le róle du De Catechizandis Rudibus de Saint Augustin dans la catéchèse missionnaire dès 710 á 847 , Studia Patristica XI.

Floristán, Casiano (1989). Para comprender el catecumenado. Estella, Verbo Divino.

García Ahumada, F.S.C., Enrique (2018). Breve Historia de la Educación Religiosa, Revista de Educación Religiosa I - 1, 139-161. Teología de la educación hoy (2016). Santiago, Chile: Ediciones Universidad Finis Terrae. La Salle y la teología de la educación (2013). Cuadernos MEL 47. Roma, Hermanos de las Escuelas Cristianas. Los cristianos en la historia de la educación (2007). Santiago, Chile: Tiberíades, 4 vols. Comienzos de la catequesis en América y particularmente en Chile. (1991). Santiago, Chile: Seminario Pontificio Mayor de los Santos Ángeles Custodios.

Gruen, S.D.B., Wolfgang (1995). Jesucristo, centro del mensaje, es el modelo de la catequesis inculturada, Consejo Episcopal Latinoamericano. Departamento de Catequesis, DECAT. Hacia una catequesis inculturada. Memorias de la II Semana Latinoamericana de Catequesis. Santafé de Bogotá, Colombia: Centro de Publicaciones del CELAM. 
Enrique García Ahumada, F.S.C. | La Didascalia, olvidada función esencial DE LA Iglesia

Mansi J.D. (1960-1961). Sacrorum Conciliorum Nova et Amplissima Collectio, Graz, Osterreich; Akademische Druck u. Verlaganstalt, 53 vols.

Paul, André. (2009). Qumrán y los esenios. El estallido de un dogma. Estella, Editorial Verbo Divino (Paris, Cerf, 2008).

Silva Gatica, SS.CC. Sergio. (2009). ¿Por qué murió Jesús? Iniciación a los Evangelios, Santiago, Chile: Ediciones Universidad Católica - Fundación Coudrin.

Vizmanos, S.J., F. (1949). Las vírgenes cristianas en la Iglesia primitiva. Estudio histórico-ideológico seguido de una antología de tratados patrísticos sobre la virginidad. Madrid, España: BAC.

Fecha de recepción: 13 de diciembre de 2018 Fecha de aceptación: 4 de marzo de 2019 